\title{
Isolation of Glycine Betaine and Proline Betaine from Human Urine Assessment of Their Role as Osmoprotective Agents for Bacteria and the Kidney
}

\author{
Stephen T. Chambers and Calvin M. Kunin \\ Department of Medicine, Ohio State University, Columbus, Ohio 43210
}

\begin{abstract}
Human urine is osmoprotective for enteric bacteria, permitting $E$. coli to grow with high concentrations of $\mathrm{NaCl}$ and other salts and even higher concentrations of sucrose and mannitol but not urea. The active material in urine is soluble in methanol and is precipitated by ammonium reineckate at acid pH. Using gel filtration and high-pressure liquid chromatography, we have identified two major osmoprotective compounds in urine. One is glycine betaine; the other is proline betaine as demonstrated by nuclear magnetic resonance, mass spectrum scanning, and chemical synthesis. Proline betaine has not been described previously to our knowledge in vertebrate tissues. It is known to be a cell volume-regulating agent for marine red algae and the euryhaline mollusk Elysia chloritica. We suggest that the presence of glycine and proline betaines in human urine may reflect an osmoprotective role for the kidney and that they protect bacteria in the urine only fortuitously.
\end{abstract}

\section{Introduction}

Enteric bacteria generally grow well in human urine despite conditions of high osmolality and low $\mathrm{pH}(1-3)$. We have shown (4) that human urine protects gram-negative bacteria that commonly produce urinary tract infections in man against the osmotic forces generated by sodium chloride and other electrolytes present in urine but not against urea. This effect can be attributed in part to physiologic urinary excretion of choline and glycine betaine (5). However, human urine is more osmoprotective for bacteria than can be accounted for by the presence of these constituents. We therefore postulated that additional osmoprotective substances are present in human urine. In this report we will provide evidence that proline betaine is present in human urine and is as biologically active as glycine betaine. To our knowledge, proline betaine has not been previously reported to exist in vertebrate tissues. It is described in several species of plants, in which it is known also as stachydrine or cadabine. It has been found in marine red algae (6) and in the extremely euryhaline mollusk Elysia chloritica. This organism utilizes proline betaine instead of free amino acids for cell volume regulation (7). We believe that the presence of both glycine betaine and proline betaine in human urine may reflect leakage of these substances

Address reprint requests to Dr. Calvin M. Kunin, Department of Medicine, Ohio State University, Starling Loving Hall, 320 West 10th Avenue, Columbus, $\mathrm{OH} 43210$.

Received for publication 25 August 1986 and in revised form 17 November 1986.

J. Clin. Invest.

(C) The American Society for Clinical Investigation, Inc.

0021-9738/87/03/0731/07 \$1.00

Volume 79, March 1987, 731-737 from the distal renal tubular cells where they serve to counteract the osmotic forces of urine. This concept is in accord with the work of Bagnasco et al. (8), who demonstrated that osmotically active organic solutes, including glycine betaine, accumulate in the rat and rabbit renal inner medulla under conditions of antidiuresis.

\section{Methods}

Collection of human urine. In the initial studies urine was obtained from six healthy men and pooled. Subsequently, individual 24 -h collections were obtained from five healthy men. These were stored at $-40^{\circ} \mathrm{C}$ until used. Permission was obtained to waive informed consent for these studies from the Human Experimentation Committee of Ohio State University.

Detection of bacterial osmoprotective activity. The osmosensitive bacterium used in these experiments was a strain of $E$. coli \#31 isolated from a patient with urinary tract infection. Its response to osmotic conditions has been well defined (4). The organism is grown in minimum medium containing glucose, dipotassium phosphate, monopotassium phosphate, trisodium citrate, magnesium sulfate, and ammonium sulfate (4). It will not grow above $0.7 \mathrm{M} \mathrm{NaCl}$ in minimum medium. Salt tolerance increases to $0.9 \mathrm{M} \mathrm{NaCl}$ when $1 \times 10^{-3} \mathrm{M}$ of glycine betaine is added and to $1.1-1.2 \mathrm{M} \mathrm{NaCl}$ in the presence of a 1:100 dilution of human urine. The $\mathrm{pH}$ of the medium is adjusted to 7.0 before use. The bacterial inoculum consists of $0.1 \mathrm{ml}$ of a 1:1,000 dilution of an overnight culture, grown in minimal medium, into $0.8 \mathrm{ml}$ of minimal medium plus $0.1 \mathrm{ml}$ of sample. This provides about $1 \times 10^{5}$ colony-forming units. The culture is incubated at $37^{\circ} \mathrm{C}$ and read at $48 \mathrm{~h}$ for light scatter at 400 $\mathrm{nm}$ with a Spectronic 20 spectrophotometer (Bausch \& Lomb, Inc., Rochester, N.Y.).

Scheme for isolation of osmoprotective compounds from human urine. The method is based on the previous observation that virtually all of the biologically active material can be extracted from human urine into methanol and precipitated at acid $\mathrm{pH}$ by ammonium reineckate (4). Choline is precipitated at alkaline $\mathrm{pH}$ and glycine betaine at acid $\mathrm{pH}$ (9). We reasoned that osmoprotective substances in urine might share the zwitter ion and quaternary ammonium characteristics of glycine betaine. In the initial purification procedure pooled human urine was lyophilized and extracted with methanol. The methanol was removed under vacuum and the residual material was dissolved in water. Gel filtration was used to remove inactive solutes. Filtered ammonium reineckate solution (1 $\mathrm{g} / 50 \mathrm{ml}$ ) was added to an equal volume of sample and alkalinized with one fifth volume of $25 \%$ sodium triphosphate solution. After $2 \mathrm{~h}$ in an ice bath the precipitate was removed by centrifugation $(3,000 \mathrm{rpm}$ for $30 \mathrm{~min}$ ). The supernatant was acidified with one fifth initial volume of $3 \mathrm{M}$ hydrochloric acid. After a further $2 \mathrm{~h}$ in an ice bath the reaction mixture was centrifuged and the supernatant was removed. The precipitates from the alkaline and acid reactions were measured by dissolving them in acetone water $(1: 4)$ and reading the absorbance at $525 \mathrm{~nm}$. The reineckate component was separated from the complex by adding water, raising the $\mathrm{pH}$ to 7.0 , and mixing with an equal volume of ethyl acetate. The phases were then separated by centrifugation $(3,000 \mathrm{rpm}$ for 20 min). This process was repeated until all the reineckate was removed from the aqueous phase that contained the active material. This was purified further by reverse-phase high-pressure liquid chromatography (HPLC) until single peaks were obtained as judged by ultraviolet absorbance. Each step of the process was monitored by determining the highest dilution at which extracts permitted the test strain of $E$. coli to grow in 
minium medium containing either 0.8 or $0.9 \mathrm{M} \mathrm{NaCl}$. The procedure was modified in later experiments by using acidified ammonium reineckate to precipitate the biologically active material directly from urine. This was followed by extraction with ethyl acetate, gel filtration, and final purification by reverse-phase HPLC.

Gel chromatography. This was conducted with a G 10 Sephadex column $(70 \times 2.6 \mathrm{~cm})$ using a peristaltic pump and a timed fraction collector (Pharmacia, Inc., Piscataway, NJ) and eluted with phosphate buffer, $\mathrm{pH}$ 7.0. Specific gravity of the eluent was measured with a handheld refractometer (National Instrument Co., Inc., Baltimore, MD).

Reverse-phase HPLC. Chromatography was performed with a Hewlett Packard $1080 \mathrm{~B}$ instrument using a semipreparative reverse-phase column (C3, 10 micron; absorbosphere, $25 \mathrm{~cm} \times 10 \mathrm{~mm}$ ) and an analytical reverse-phase column $(C 18,5$ micron; nucleosil, $25 \mathrm{~cm} \times 4.6 \mathrm{~mm})$ at room temperature (Alltech Associates, Inc., Deerfield, IL). The mobile phase was pure water (HPLC grade, Burdick and Jackson Laboratories, Inc., Muskegon, MI). It was filtered (model FH, 0.5 micron; Millipore/ Continental Water Systems, Bedford, MA) and degassed by stirring under vacuum $(20 \mathrm{~mm} \mathrm{Hg}$ ) before use. The solvent flow rate was $1.0 \mathrm{ml} / \mathrm{min}$ for the analytical column and $5 \mathrm{ml} / \mathrm{min}$ for the semipreparative column. A continuous record of ultraviolet absorbance $(205 \mathrm{~nm})$ of eluent was made on a chart recorder. Timed fractions of the eluent containing osmoprotectant bioactivity were evaporated under vacuum, redissolved in water, and further purified by repeated chromatography. The final product was dissolved in methanol and dried under a continuous stream of ultrahigh-purity nitrogen in preparation for mass and nuclear magnetic resonance spectroscopy. In later experiments to quantify both glycine and proline betaine timed fractions were collected from the semipreparative column and those containing bioactivity were evaporated under vacuum, redissolved in water, and applied to the analytical column. The identity of the ultraviolet light absorbance peaks was made by coelution with standards added to the sample and confirmed by bioactivity and nuclear magnetic resonance (NMR) ${ }^{1}$ spectra. Quantitation was made by comparing the ultraviolet light absorbance produced with a 10- $\mu$ injection of the sample with a standard curve generated by $10-\mu$ injections of standard solutions.

$N M R$ and mass spectroscopy. Scans were performed at the Ohio State University Chemical Instruments Center. NMR spectra were obtained with samples dissolved in deuterated methanol (Aldrich Chemical Co., Milwaukee, WI) on a Bruker AM-500 spectrometer. Proton spectra were recorded at $500.13 \mathrm{MHz}$ and chemical shifts reported relative to the residual proton signal from deuterated methanol. Resonances were identified by comparison with the spectrum of proline and in selective decoupling experiments. Natural abundance ${ }^{13} \mathrm{C}$ NMR spectra were collected at $125.76 \mathrm{MHz}$ and chemical shifts were reported relative to the deuterated solvent. Spectral editing was performed using distortionless enhanced polarization transfer pulse sequencing. Mass spectrums were obtained by fast bombardment with a Kratos MS 30 mass spectrometer.

Chemicals. Chemical reagents were of the highest purity available. Glycine betaine, choline, butyrocholine, beta butyrobetaine, gamma amino butyric acid, phosphorylethanolamine, glycerophosphorylethanolamine, carnitine, trigellonine, proline, histidine, methionine, serine, glutamic acid, taurine, hydroxyproline, thiamine, hippuric acid, and ammonium reineckate were all purchased from Sigma Chemical Co., St. Louis, MO.

Synthesis of proline betaine. Proline betaine was synthesized by the method of Cornforth and Henry (10). $1 \mathrm{~g}$ of proline (Sigma Chemical Co.) was added to a suspension of $2 \mathrm{~g}$ silver oxide, (Aldrich Chemical Co.) in $20 \mathrm{ml}$ of methanol (Burdick and Jackson Laboratories, Inc.) When the formation of a silver compound appeared to be complete 2 $\mathrm{ml}$ of iodomethane was added and the solution was left at room temperature overnight. The next day more iodomethane was added and the mixture was heated by reflux for $3 \mathrm{~h}$. The product was filtered and dried under vacuum. $1 \mathrm{ml}$ of concentrated hydrochloric acid was added to the

1. Abbreviation used in this paper: NMR, nuclear magnetic resonance.
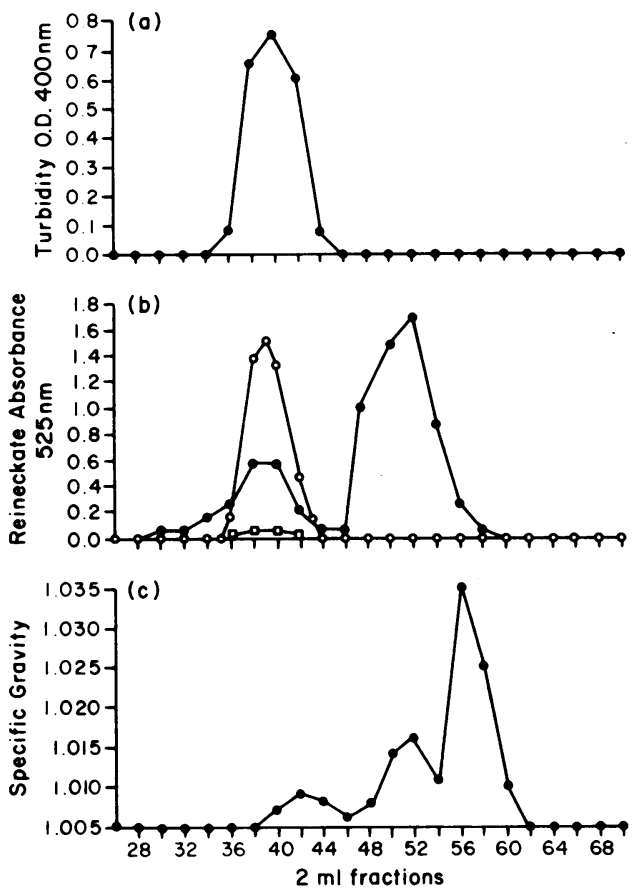

Figure 1. Chromatography of a methanol extract of pooled human urine on Sephadex G 10. (a) Growth of E. coli in the presence of 0.9 $\mathrm{M} \mathrm{NaCl}$ as measured by turbidity. (b) Acid reineckate precipitable material (solid circles), alkaline reineckate precipitable material (open squares), and a glycine betaine standard (open circles). (c) Elution of solutes from the column.

crystals and the solution evaporated from ethanol to dryness. The product was recrystallized twice with ethanol and the prisms were crushed and washed in ice cold methanol. The synthetic proline betaine gave a melting point of $222.5-223^{\circ} \mathrm{C}$, as reported (10). The exact mass on fast atom bombardment was 144.1038 (dev. 1.4 millimass units) with confirmation of the structure by proton and carbon NMR scans.

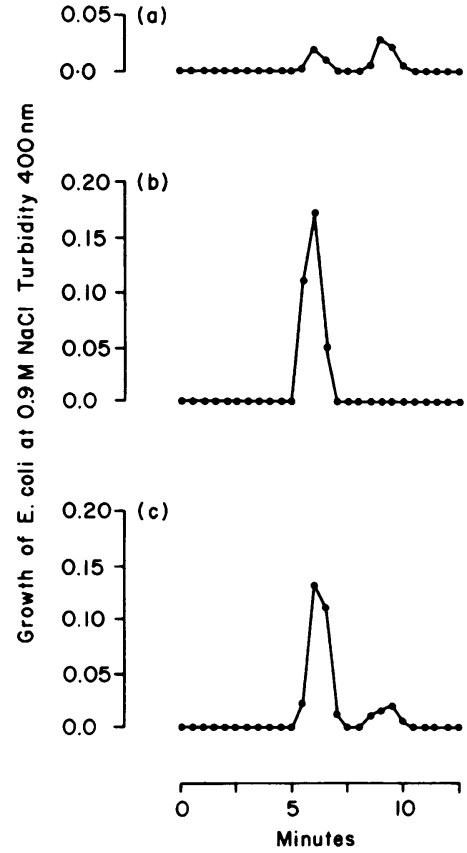

Figure 2. HPLC of osmoprotective material recovered from human urine after gel filtration and acid reineckate precipitation. (a) Biologically active material recovered from the column. (b) Betaine standard. (c) Betaine standard added to the biologically active material. 


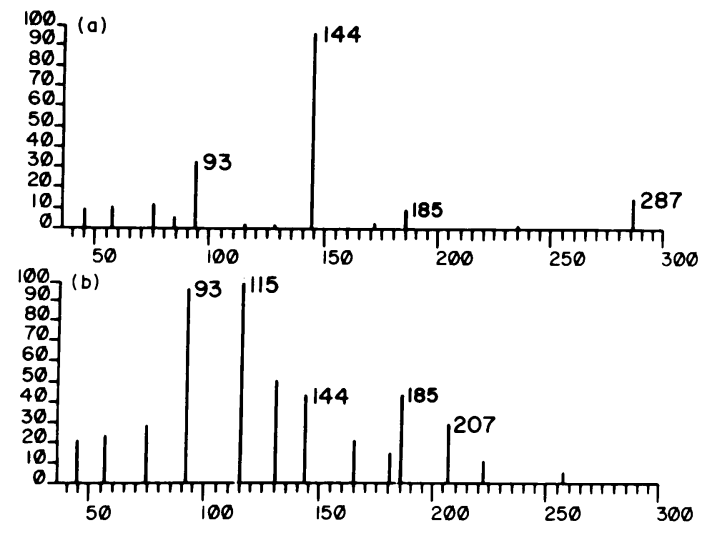

Figure 3. Mass spectra of synthesized proline betaine (top) and the biologically active material purified by HPLC (bottom). This reveals a peak at 144 atomic mass units $\left(\mathrm{M}+\mathrm{H}^{+}\right)$. A dimer of proline betaine is also present in the top spectrum, 287 atomic mass units $\left(2 \mathrm{M}+\mathrm{H}^{+}\right)$. Other peaks from the biologic sample represent complexes of matrix (glycerol mass 92) and hydrogen, sodium and potassium.

\section{Results}

Isolation of proline betaine from human urine. Residue from the methanol extract of lyophilized pooled human urine was dissolved in water and chromatographed on a G 10 Sephadex column. The first eluent peak contained the biologically active material (Fig. $1 a$ ). This was coincident with the elution of the first peak of acid reineckate and a small amount of alkaline reineckate precipitable material (Fig. $1 \mathrm{~b}$ ). The second peak of acid reineckate precipitable material was not biologically active and was associated with the remainder of the solutes (Fig. $1 \mathrm{c}$ ).
Glycine betaine was added to the column and detected by precipitation with acidified ammonium reineckate. It eluted at the same volume as the biologically active peak.

The biologically active peak was pooled, precipitated with acid reineckate solution and extracted with ethyl acetate as described above. The aqueous residue was chromatographed by reverse-phase HPLC with the $\mathrm{C} 18$ analytic column. Two biologically active peaks were identified (Fig. 2 a). The first peak coeluted with a known standard of glycine betaine at $5.1 \mathrm{~min}$. The second peak, which eluted at $7.7 \mathrm{~min}$, contained the unknown. The second active peak was pooled and rechromatographed repeatedly until a single peak at $205 \mathrm{~nm}$ was obtained.

Mass spectral analysis. On mass spectral analysis this peak gave an exact mass of 144.1033 (dev. 0.8 millimass units) (Fig. 3), suggesting a formula of $\mathrm{C}_{7} \mathrm{H}_{14} \mathrm{NO}_{2}$. The proton NMR (Fig. 4) and 13-carbon spectra (Fig. 5) showed chemical shifts and coupling typical of a quaternary amine. Proton decoupling spectra and spectral editing of the 13-carbon scan showed spacial relationships consistent with a pyrrole ring and allowed assignment of protons to carbon atoms. These data suggested the compound was proline betaine. Note the similarity with the structure of glycine betaine (Fig. 6). Proline betaine was therefore synthesized by the method of Conforth and Henry (10). The proton and carbon NMR spectra of the synthetic (30 mg) and biologic samples $(0.5 \mathrm{mg})$ were essentially the same but showed small variations due to concentration and $\mathrm{pH}$ effects. These were also consistent with spectra that had been published previously (Table I) $(11,12)$. Additional proof of identity included the findings that synthetic proline betaine eluted from reverse-phase HPLC at the same volume as the unknown and the biologic activity of proline betaine was the same for the chemical synthesized material and the purified compound extracted from the urine. Pro-

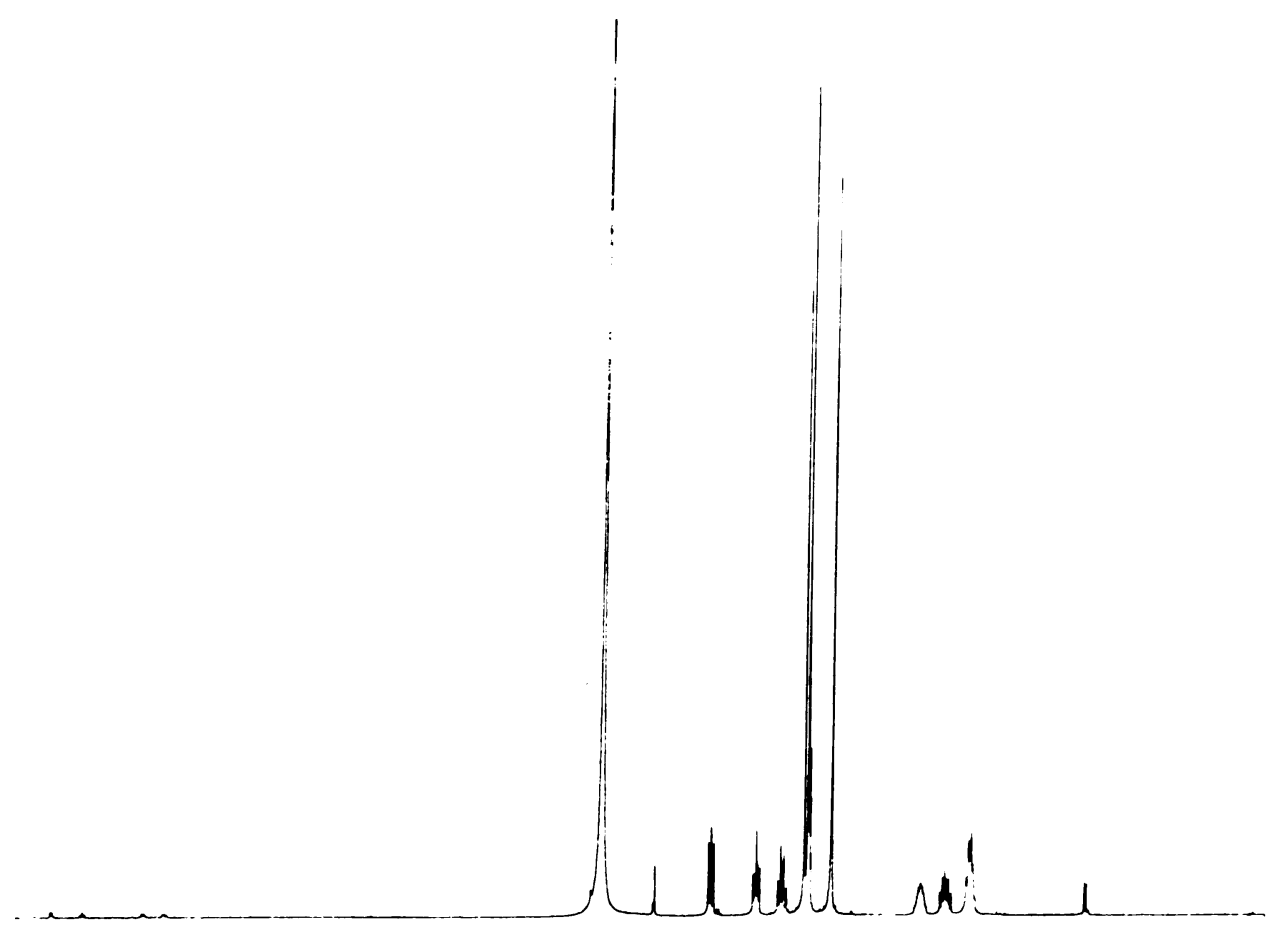




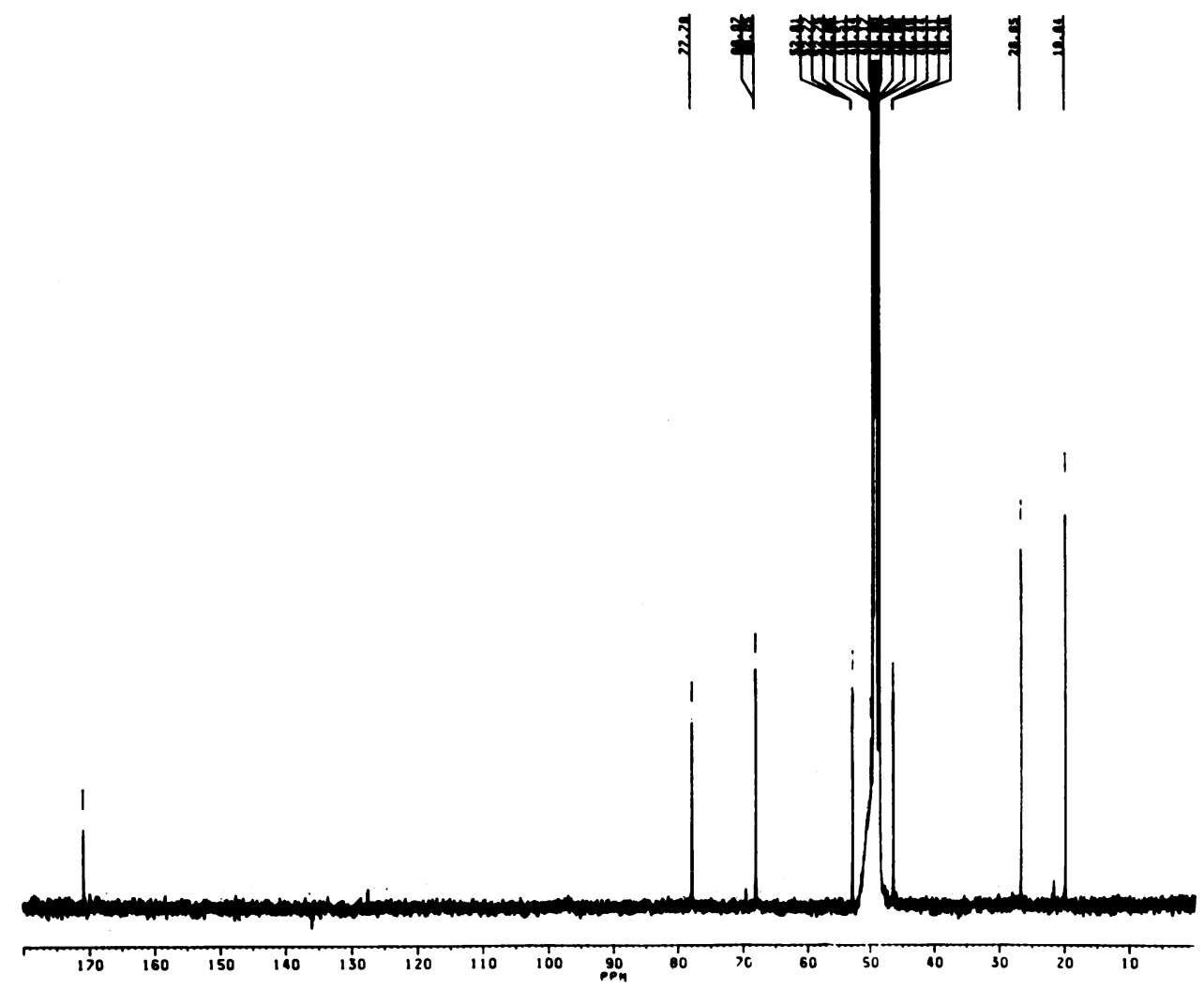

Figure 5. The $125.67 \mathrm{MHz}{ }^{13} \mathrm{C}$ NMR spectrum of proline betaine isolated from human urine.

line betaine at $1 \times 10^{-3} \mathrm{M}$ was found to permit $E$. coli to grow at $0.9 \mathrm{M} \mathrm{NaCl}$ with a similar endpoint to glycine betaine. When the two compounds were tested together in a box titration there was no detectable synergistic effect (Table II).

Quantitative recovery of glycine betaine and proline betaine from human urine. To determine the daily excretion of glycine and proline betaine in human urine, 24-h urine collections were obtained from five healthy subjects. An aliquot of $500 \mathrm{ml}$ was precipitated with acidified ammonium reineckate, which was removed by ethyl acetate extraction, and the aqueous phase was chromatographed on Sephadex G 10. The biologically active fraction was then subjected to reverse-phase HPLC on the C 3 semipreparative column. Two major peaks, coinciding with glycine betaine and proline betaine and the greatest osmoprotective activity, were detected in the urine extracts of each subject (Fig. 7). Additional, less active osmoprotective compounds were also present in human urine. These remain to be identified. Bacterial growth shown in the early peaks may have been diminished by coelution of osmotically active material.

Each of the major peaks were rechromatographed on HPLC using the analytic C 18 column. Standard curves on HPLC for
Figure 6. Chemical structures of glycine betaine and proline betaine revealing their close similarity as noted by hatched lines. pure glycine betaine and proline betaine were obtained (Fig. 8). The daily urinary excretion of glycine betaine and proline betaine are shown in Table III. Recovery of external standards of proline and glycine betaine were $81 \%$ and $86 \%$ respectively. It can be seen that there was considerable variation in the amount of each of the betaines recovered in urine from each subject, but the amount of the two betaines recovered in the urine generally paralleled each other. For example, subject S.C. was the highest and subject C.K. the lowest excretor of both compounds. To examine this phenomenon further the concentration of the betaines in the pooled 24-h urine sample was compared with osmoprotective activity and osmolality (Table IV). Note the close correlation between the concentration of the betaines and osmoprotective activity in urine. Although there was a trend toward an inverse relation between urinary osmolality and concentration of the betaines this was not statistically significant, possibly due to small numbers.

Screening of candidate compounds for osmoprotective activity. A series of compounds was screened from bacterial osmoprotective activity because compounds had been previously described to be active or because they were highly soluble in water or known to be present in urine and possessed a quaternary ammonium group similar to choline and glycine betaine (Table V). Proline betaine was added to this list after it had been isolated from human urine and synthesized. The most active compounds are glycine betaine, proline betaine and butyrylcholine. Glycerophosphorylcholine, described by Bagnasco et al. (8) to be an osmotically active organic solute, and carnitine were less active osmoprotective agents. Because both of these compounds are precipitated by acidified reineckate, they might account for some of the unidentified compounds recovered from human urine. 
Table I. Characteristics of Proton and Carbon NMR Spectra of Proline Betaine Confirming the Identity of the Osmoprotective Substance Isolated from Human Urine

\begin{tabular}{|c|c|c|c|c|}
\hline & \multicolumn{2}{|c|}{ Synthetic proline betaine, $30 \mathrm{mg}$} & \multicolumn{2}{|c|}{ Biologic proline betaine, $0.5 \mathrm{mg}$} \\
\hline & Proton & Carbon & Proton & Carbon \\
\hline $\mathrm{C} 2$ & $\begin{array}{l}\mathrm{dd}, 4.58 \mathrm{ppm} \\
\mathrm{J}=8.96 \& 8.95 \mathrm{~Hz}(\mathrm{z}) \\
\mathrm{I}=1.017\end{array}$ & s, $74.57 \mathrm{ppm}$ & $\begin{array}{l}\mathrm{dd}, 4.00 \mathrm{ppm} \\
\mathrm{J}=8.85 \& 8.78 \mathrm{~Hz}(\mathrm{z}) \\
\mathrm{I}=0.995\end{array}$ & $\mathrm{CH}, * 77.9 \mathrm{ppm}$ \\
\hline $\mathrm{C} 3$ & $\begin{array}{l}\mathrm{m}, 2.38-2.48 \mathrm{ppm} \\
\mathrm{I}=1.306 \\
\mathrm{~m}, 2.55-2.65 \mathrm{ppm} \\
\mathrm{I}=1.297\end{array}$ & s, $25.84 \mathrm{ppm}$ & $\begin{array}{l}\mathrm{m}, 2.25-2.55 \mathrm{ppm} \\
\mathrm{I}=1.014 \\
\mathrm{~m}, 2.45-2.55 \mathrm{ppm} \\
\mathrm{I}=1.007\end{array}$ & $\mathrm{CH}_{2}, 26.65 \mathrm{ppm}$ \\
\hline $\mathrm{C} 4$ & $\begin{array}{l}\mathrm{m}, 2.15-2.30 \mathrm{ppm} \\
\mathrm{I}=2.449\end{array}$ & $\mathrm{~s}, 19.83 \mathrm{ppm}$ & $\begin{array}{l}\mathrm{m}, 2.10-2.20 \mathrm{ppm} \\
\mathrm{I}=2 / 183\end{array}$ & $\mathrm{CH}_{2}, 19.84 \mathrm{ppm}$ \\
\hline $\mathrm{C} 5$ & $\begin{array}{l}\mathrm{m}, 3.65-3.75 \mathrm{ppm} \\
\mathrm{I}=2.591 \\
\mathrm{~m}, 3.78-3.84 \mathrm{ppm} \\
\mathrm{I} \text { (included in above) }\end{array}$ & s, 66.99 ppm & $\begin{array}{l}\mathrm{m}, 3.45-3.55 \mathrm{ppm} \\
\mathrm{I}=1.120 \\
\mathrm{~m}, 3.65-3.75 \mathrm{ppm} \\
\mathrm{I}=1.121\end{array}$ & $\begin{array}{l}\mathrm{CH}_{2}, 68.05 \mathrm{ppm} \\
\mathrm{Jcn}=25 \mathrm{~Hz}\end{array}$ \\
\hline $\mathrm{CH}_{3}$ & $\begin{array}{l}\mathrm{s}, 3.20 \mathrm{ppm} \\
\mathrm{I}=3.86\end{array}$ & s, $46.92 \mathrm{ppm}$ & $\begin{array}{l}\mathrm{s}, 3.15 \mathrm{ppm} \\
\mathrm{I}=3.599\end{array}$ & $\begin{array}{l}\mathrm{CH}_{3}, 46.41 \mathrm{ppm} \\
\mathrm{Jcn}=37 \mathrm{~Hz}\end{array}$ \\
\hline $\mathrm{CH}_{3}$ & $\begin{array}{l}\mathrm{s}, 3.42 \mathrm{ppm} \\
\mathrm{I}=3.85\end{array}$ & $\mathrm{~s}, 52.94 \mathrm{ppm}$ & $\begin{array}{l}\text { s, } 3.35 \text { ppm } \\
\text { N.A. }\end{array}$ & $\begin{array}{l}\mathrm{CH}_{3}, 52.77 \mathrm{ppm} \\
\mathrm{Jcn}=37 \mathrm{~Hz}\end{array}$ \\
\hline $\mathrm{COOH}$ & & 168.36 & & 170.76 \\
\hline
\end{tabular}

Variations are due to concentration and $\mathrm{pH}$ effects. * From distortionless enhanced polarization transfer scan. s, singlet; dd, double doublet; $\mathrm{m}$, multiplet; I, integrated area.

\section{Discussion}

Bacterial cells are able to endure wide variations in external osmotic forces. They are protected by a series of adaptive mechanisms controlled by osmotic tolerance genes (13). Osmosensitive proteins, located in the outer membrane, trigger regulatory responses to osmotic stress. These responses include alterations in porin proteins $(14,15)$, potassium transport $(16,17)$, biosynthesis of protective oligosaccharides (18), and uptake and synthesis of osmoprotective molecules. The major osmoprotective substances are glycine betaine, choline, proline, and glutamine (13). They are termed "compatible solutes" because they ac-

Table II. Effect of Combinations of Glycine Betaine and Proline Betaine on Growth of E. coli in the Presence of $0.9 \mathrm{M} \mathrm{NaCl}$

\begin{tabular}{lllllll}
\hline & \multicolumn{7}{c}{ Glycine betaine } \\
\cline { 3 - 7 } & & 0 & $10^{-3}$ & $10^{-4}$ & $10^{-5}$ & $10^{-6}$ \\
\hline \multirow{2}{*}{ Proline betaine } & 0 & 0 & 4 & 4 & 2 & 0 \\
& $10^{-3}$ & 1 & 4 & 4 & 3 & 1 \\
& $10^{-4}$ & 2 & 4 & 4 & 3 & 1 \\
& $10^{-5}$ & 1 & 4 & 4 & 2 & 1 \\
& $10^{-6}$ & 0 & 4 & 4 & 2 & 0
\end{tabular}

The intensity of growth after $48 \mathrm{~h}$ is shown on a scale of 1 to 4 . 1 , light; 2 , moderate; 3 , heavy; 4 , maximum. cumulate intracellularly in the presence of high extracellular solute concentrations and protect the cell from dehydration. Proline and glycine betaine have been reported to also stabilize membrane phospholipids (19) and protect enzymes against heat inactivation (20). Proline betaine has been shown to enhance the

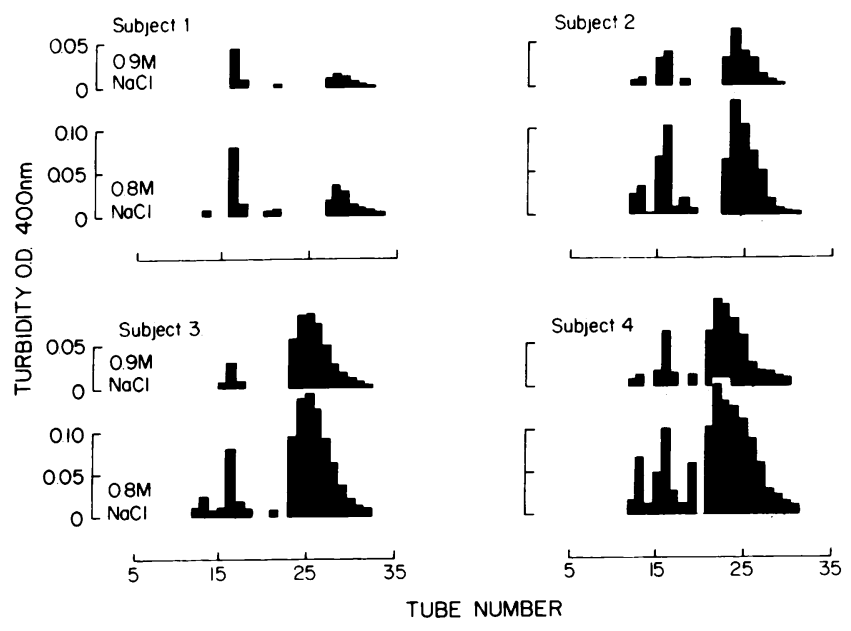

Figure 7. HPLC of extracts of biologically active material obtained from the urine of four human subjects. These reveal two major peaks of activity, as measured by turbidity, that permit $E$. coli to grow in 0.9 $\mathrm{M} \mathrm{NaCl}$ and possibly several more active fractions that protect against $0.8 \mathrm{M} \mathrm{NaCl}$. 


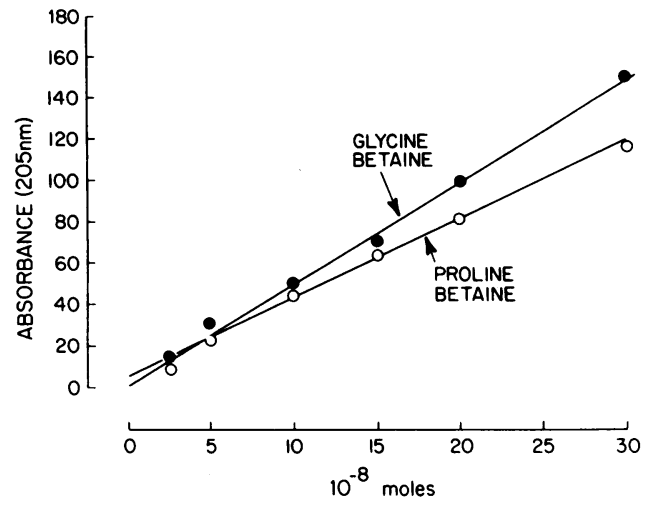

Figure 8. Standard curves for assay by HPLC. Linear regression for glycine betaine: $\mathrm{y}=0.06+4.99 \mathrm{X}, \mathrm{r}=0.998$; for proline betaine: $\mathrm{y}$ $=6.92+3.69 \mathrm{X}, \mathrm{r}=0.999$.

anaerobic growth and nitrogen fixation of Klebsiella pneumoniae in media of inhibitory osmotic and to be more active in this respect than glycine betaine (21).

The presence of osmoprotective agents for bacteria in human urine suggested to us (4) that these substances may be present in the kidney and perform a similar osmoprotective function. We proposed that they might accumulate intracellularly and may thereby protect renal tubular cells from the high osmotic forces generated as the glomerular filtrate becomes increasingly concentrated within the tubular lumen. Bagnasco et al. (8) developed independently a similar hypothesis based on their finding that large amounts of glycine betaine, sorbitol, glycerophosphoryl choline, and inositol accumulated in the cells of the inner renal medulla but not in the cortex during antidiuresis in rabbits. We have reported that there is increased osmoprotective activity for $E$. coli in renal papillae in several animal species and have shown in rabbits that this is decreased during diuresis and enhanced by increased osmotic loads (22). These findings suggest that the recovery of osmoprotective substances in urine may reflect leakage of osmoprotective substances from renal cellular sites and fortuitously support bacterial growth in hyperosmotic urine.

Proline betaine is a powerful osmoprotective agent for bacteria $(21)$ and various forms of marine life $(6,7)$, but it has not been detected previously to our knowledge in vertebrate tissues. The relatively large amounts of proline betaine excreted into the urine suggests that it may have an important metabolic role.

Table III. Quantitative 24-h Urinary Recovery of Glycine Betaine and Proline Betaine from Five Healthy Men

\begin{tabular}{llrllll}
\hline & \multicolumn{3}{l}{ Urinary recovery } \\
\cline { 2 - 7 } Subject & \multicolumn{2}{l}{ Glycine betaine } & \multicolumn{2}{l}{ Proline betaine } & \multicolumn{2}{l}{ Total betaines } \\
\hline & \multicolumn{1}{l}{$\mathrm{mol}^{*}$} & $\mathrm{mg}$ & $\mathrm{mol}$ & $\mathrm{mg}$ & $\mathrm{mol}$ & $\mathrm{mg}$ \\
& & & & & & \\
S.C. & 7.28 & 85.2 & 5.33 & 76.2 & 12.61 & 161.4 \\
W.C. & 0.79 & 9.2 & 2.60 & 37.1 & 3.39 & 46.3 \\
J.R. & 1.28 & 15.0 & 1.02 & 14.5 & 2.30 & 29.5 \\
Q.C. & 0.55 & 6.4 & 0.70 & 9.4 & 1.25 & 15.8 \\
C.K. & 0.48 & 5.6 & 0.16 & 2.4 & 0.64 & 8.0 \\
\hline
\end{tabular}

$* 1 \times 10^{-4}$
Table IV. Mean Concentration of Glycine Betaine and Proline Betaine in 24-h Collections of Urine from Five Healthy Men Compared with Osmoprotective Activity for E. coli and Urine Osmolality

\begin{tabular}{|c|c|c|c|c|c|}
\hline \multirow[b]{3}{*}{ Subject } & \multirow{2}{*}{\multicolumn{3}{|c|}{ Betaines }} & \multirow{3}{*}{$\begin{array}{l}\text { Osmoprotection } \\
\text { Maximum } \\
\text { dilution } \\
\text { vs. } 0.9 \mathrm{M} \mathrm{NaCl}\end{array}$} & \multirow{3}{*}{$\begin{array}{l}\text { Urine } \\
\text { osmolality }\end{array}$} \\
\hline & & & & & \\
\hline & Glycine & Proline & Total & & \\
\hline & $\times 10^{-4} \mathrm{M}$ & $\times 10^{-4} M$ & $\times 10^{-4} \mathrm{M}$ & & $\mathrm{mOsm} / \mathrm{kg}$ \\
\hline S.C. & 4.92 & 3.60 & 8.52 & 128 & 510 \\
\hline W.C & 1.05 & 3.46 & 4.51 & 128 & 868 \\
\hline J.R. & 1.16 & 0.92 & 2.08 & 64 & 702 \\
\hline Q.C. & 0.94 & 1.13 & 2.17 & 64 & 872 \\
\hline C.K. & 0.74 & 0.25 & 0.99 & 32 & 1011 \\
\hline
\end{tabular}

The source of proline betaine is unknown. It was not described by Bagnasco et al. (8) to be present in rabbit or rat kidney tissue. Further studies are needed to determine how proline betaine is synthesized in man, where the major sites of synthesis are located and whether our speculations concerning its role as a renal osmoprotective agent can be established.

The amount and concentration of glycine betaine and proline betaine excreted in human urine could be correlated with osmoprotective activity. This suggests that these substances, at least in part, account for the bacterial osmoprotective activity of human urine. The inverse relation between excretion of the betaines and urinary osmolality suggests that they might be retained during antidiuresis as protective organic solutes within the tubular cells and excreted into the urine during diuresis when they are

Table V. Ability of Various Compounds to Be Precipitated by Ammonium Reineckate and to Permit E. coli to Grow in the Presence of $\mathrm{NaCl}$ Added to Minimum Medium

\begin{tabular}{|c|c|}
\hline Activeness & Compounds \\
\hline Inactive* & Methionine, thiamine, hippuric acid \\
\hline Weak $(0.7 \mathrm{M})^{*}$ & $\begin{array}{l}\text { Hydroxyproline, histidine, serine, glutamate, } \\
\text { taurine, sorbitol, inositol, phosphoryl- } \\
\text { ethanolamine, glycerophosphoryletha- } \\
\text { nolamine }\end{array}$ \\
\hline Moderate $(0.8 \mathrm{M})^{\ddagger}$ & Choline \\
\hline Strong $(0.9 \mathrm{M})^{\ddagger}$ & Butyrylcholine \\
\hline Weak $(0.7 \mathrm{M})^{\S}$ & $\begin{array}{l}\text { Phosphorylcholine, gamma amino butyric } \\
\text { acid, trigellonine }\end{array}$ \\
\hline Moderate $(0.8 \mathrm{M})^{\S}$ & $\begin{array}{l}\text { Proline, glycerophosphorylcholine, beta bu- } \\
\text { tyrobetaine, carnitine }\end{array}$ \\
\hline Strong $(0.9 \mathrm{M})^{\S}$ & Glycine betaine, proline betaine \\
\hline
\end{tabular}

In this experiment the strain of $E$. coli grew in up to $0.6 \mathrm{M} \mathrm{NaCl}$. Molar measurements signify highest concentrations of $\mathrm{NaCl}$ in which $E$. coli grew in presence of $1 \times 10^{-3} \mathrm{M}$ of each compound. * Not precipitated by reineckate; ${ }^{*}$ precipitated by reineckate at alkaline $\mathrm{pH}$; ${ }^{8}$ precipitated by reineckate at acid $\mathrm{pH}$. 
no longer needed. However, this hypothesis remains to be proven.

The rationale for attempting to identify additional bacterial osmoprotective agents in urine was our observation that human urine was more osmoprotective than could be accounted for by the presence of choline or glycine betaine. Because proline betaine is not more active than glycine betaine and does not behave synergistically, we remain unable to account for the remarkable osmoprotective activity of human urine for bacteria. This may be explained possibly by the presence in urine of other nutrients that are not osmoprotective by themselves but are important growth factors for $E$. coli and work in concert with osmoprotective substances.

In view of the apparent importance of glycine betaine and proline betaine in protecting bacteria from osmotic forces generated by electrolytes in urine it may be possible to synthesize betainelike compounds that compete for uptake of glycine and proline betaine by bacteria but do not enter cells of the host. Under conditions of antidiuresis these compounds may inhibit growth of bacteria and have potential use in the treatment of urinary tract infections.

\section{Acknowledgments}

We wish to thank Dr. D. N. Gerber and Dr. D. Mays of the Department of Pharmacology for their helpful suggestions and aid in performance of the HPLC studies, Dr. C. Cottrell and Mr. R. Weisenberger of the Ohio State University Campus Chemical Instruments Center for their guidance in performance and interpretation of the NMR and mass spectroscopy studies, and Mr. J. Rudy for technical assistance.

This work was supported by the Seed Grant Program of Ohio State University and the Central Ohio chapter of the National Kidney Foundation.

\section{References}

1. Asscher, A. W., M. Sussman, W. E. Waters, et al. 1966. Urine as a medium for bacterial growth. Lancet. 2:1037-1041.

2. Kaye, D. 1968. Antibacterial activity of human urine. J. Clin. Invest. 47:2374-2390.

3. Mulholland, S. G., J. R. Perez, and J. Y. Gillenwater. 1969. The antibacterial properties of urine. Invest. Urol. 6:569-581.

4. Chambers, S., and C. M. Kunin. 1985. The osmoprotective properties of urine for bacteria: the protective effect of betaine and human urine against low $\mathrm{pH}$ and high concentrations of electrolytes, sugars and urea. J. Infect. Dis. 152:1308-1315.

5. Rennick, B. R. 1981. Renal tubule transport of organic ions. Am. J. Physiol. 240:F83-F89.
6. Blunden, G., S. M. Gordon, W. F. McLean, and G. R. Keysell. 1983. Beta stachydrine, a novel betaine from Griffithsia flosculosa. Phytochemistry (Oxf.). 22:293.

7. Pierce, S. K., S. C. Edwards, P. H. Mazzochi, L. J. Klingler, and M. K. Warren. 1984. Proline betaine: a unique osmolyte in an extremely euryhaline osmoconformer. Biol. Bull. (Woods Hole). 167:495-500.

8. Bagnasco, S., R. Balaban, H. M. Fales, Y.-M. Yang, and M. Burg. 1986. Predominant osmotically active organic solutes in rat and rabbit renal medullas. J. Biol. Chem. 261:5872-5877.

9. Bandelin, F. J., and R. E. Pankratz. 1953. The estimation of betaine and choline in mixtures. J. Am. Pharm. Assoc. 42:442-443.

10. Cornforth, J. W., and A. J. Henry. 1952. The isolation of Lstachydrine from the fruit of Capparis tomentosa. J. Chem. Soc. (Lond.). 1:601-602.

11. Ahmad, V. U., A. Basha, and A.-U. Rahman. 1974. Structure and C-13 NMR spectrum of cadabine. Pak. J. Sci. Ind. Res. 17:109110.

12. Pettigrew, G. W., and G. M. Smith. 1977. Novel N-terminal protein blocking group identified as dimethylproline. Nature (Lond.). 265:661-662.

13. Le Rudulier, D., A. R. Strom, A. M. Dandekar, L. T. Smith, and R. C. Valentine. 1984. Molecular biology of osmoregulation. Science (Wash. DC). 224:1064-1068.

14. Van Alphen, W. V., and B. Lugtenberg. 1977. Influence of osmolarity of the growth medium on the outer membrane protein pattern of Escherichia coli. J. Bacteriol. 131:623-630.

15. Lugtenberg, B., R. Peters, A. Bernheimer, and W. Benendson. 1976. Influence of cultural conditioners and mutations on the composition of the outer membrane proteins of E. coli. Mol. \& Gen. Genet. 147:251-262.

16. Rhoads, D. H., F. B. Water, and W. Epstein. 1976. Cation transport in E. coli VIII. Potassium transport mutants. J. Gen. Physiol. 67: 325-341.

17. Laimins, L. A., D. H. Rhoads, K. Altendorf, and W. Epstein. 1978. Identification of the structural proteins of an ATP-driven potassium transport system in E. coli. Proc. Natl. Acad. Sci. USA. 75:3216-3219.

18. Kennedy, E. P. 1982. Osmotic regulation and the biosynthesis of membrane derived oligosaccharides in E. coli. Proc. Natl. Acad. Sci. USA. 79:1092-1095.

19. Rudolph, A. S., J. H. Crowe, and L. M. Crowe. 1986. Effect of three stabilizing agents-proline, betaine and trehalose-on membrane phospholipids. Arch. Biochem. Biophys. 245:134-143.

20. Paleg, L. G., T. J. Douglas, A. van Daal, and D. B. Keech. 1981. Proline, betaine and other organic solutes protect enzymes against heat inactivation. Aust. J. Plant Physiol. 8:107-114.

21. Le Rudulier, D., T. Bernard, and G. Goas. 1984. Osmoregulation in Klebsiella pneumoniae: enhancement of anaerobic growth and nitrogen fixation under stress by proline betaine, -amino butyrobetaine, and other related compounds. Can. J. Microbiol. 30:299-305.

22. Chambers, S., and C. M. Kunin. 1986. Osmoprotective activity in the kidney for E. coli, location and response to osmotic loads. Clin. Res. 34:970A. (Abstr.) 